\title{
Leuconostoc pseudomesenteroides
}

National Cancer Institute

\section{Source}

National Cancer Institute. Leuconostoc pseudomesenteroides. NCI Thesaurus. Code C86498.

A species of facultatively anaerobic, gram positive, cocci shaped bacteria in the phylum Firmicutes. This species is nonmotile, catalase and oxidase negative, produces acid from arabinose and hydrolyzes esculin. L. psuedomesenteroides is an opportunistic nosocomial pathogen in patients with underlying disease. 